\title{
Changes of Linoleic, Arachidonic and Eicosapentaenoic Acids in Rat Platelet, Aorta and Plasma Lipids after Changing from a Sardine Oil Diet to a Corn Oil Diet
}

\author{
Masataka Ishinaga, Hitoshi Takamura, ${ }^{*}$ Hiroshi Narita* \\ and Makoto KITO* \\ Department of Food and Nutrition, Hiroshima Women's University, \\ Ujina-Higashi, Hiroshima 734, Japan \\ * Research Institute for Food Science, Kyoto University, \\ Uji, Kyoto 611, Japan \\ Received April 8, 1985
}

\begin{abstract}
When rats were fed on a diet containing sardine oil (SO) for 10 days, 20:5 (eicosapentaenoic acid) was incorporated into the platelet, aorta and plasma lipids. The 20:5/20:4 (arachidonic acid) ratios of phospholipids were higher in platelets than in aortas. When the diet was changed from SO to corn oil (CO), the levels of $20: 5$ in the plasma lipids and platelet phospholipids decreased with an increase of 20:4. Although the 20:5 levels of phospholipids in the aortas decreased, 20:4 did not increase during feeding with the $\mathrm{CO}$ diet for 4 days. The 20:5/20:4 ratios of the phosphatidylcholine in platelets and aortas rapidly changed from 5.0 and 1.1 to 2.4 and 0.6 , respectively. The linoleic acid level of phosphatidylcholine in platelets and aortas increased rapidly by changing from the SO diet to the CO diet, but this fatty acid was not incorporated into phosphatidylinositol of the platelets and aortas.
\end{abstract}

There are many reports on the effects of dietary fats on cardiovascular disease ${ }^{1,2)}$ and production of prostaglandins. ${ }^{3 \sim 6)}$ Budowski recently reviewed the nutritional effects of $n-3$ polyunsaturated fatty acids. ${ }^{7)}$ When human and experimental animals were given a diet containing fish oil, eicosapentaenoic acid (20:5) was incorporated into the phospholipids of platelets or aortas, and platelet aggregation was depressed, bleeding time was prolonged and the vascular responsiveness of aortas to various agents was decreased. ${ }^{2,5,8 \sim 15)}$ However, there is no report on the relationship between these physiological parameters and the content of $20: 5$ in the individual phospholipids of tissues modified with fish oil. We have previously described that the depressed aggregation of washed platelets from rats fed on a sardine oil diet (SO diet) was gradually restored during feeding with a corn oil diet (CO diet). ${ }^{15)}$

This paper deals with the relationship of changes in linoleic acid $(18: 2)$, arachidonic acid $(20: 4)$ and $20: 5$ of the individual phospholipids among plasma, platelets and aortas after changing from an SO diet to a $\mathrm{CO}$ diet.

\section{MATERIALS AND METHODS}

Animals and diets. Male Sprague-Dawley rats (8 weeks old) were used. The basal diet was prepared with the following weight percentage composition: vitamin-free casein, 25; corn starch, 38; sucrose, 21; salt mixture, 6; vitamin mixture, 2 ; and cellulose powder, $8 .{ }^{16)} \mathrm{CO}$ or SO (from Nippon Reizo Co., Ltd.) was added at $20 \%(\mathrm{w} / \mathrm{w})$ to the basal diet. Table I shows the fatty acid compositions of $\mathrm{CO}$ and SO. The peroxide values of $\mathrm{CO}$ and SO were less than 3.0. Tocopherol $(250 \mathrm{mg})$ and butylated hydroxytoluene (BHT, $500 \mathrm{mg}$ ) were added to $1 \mathrm{~kg}$ of each diet. The diets were prepared every day and fed ad libitum to a group of 7 rats. After 10 days on the SO diet, the rats were fed on the $\mathrm{CO}$ diet for an additional $1,2,3$ and 4 days.

Preparation of washed platelets and aortas. Preparation of washed platelets was carried out according to the previous paper. ${ }^{15)}$ A $1300 \times g$ supernatant of platelet-rich plasma was used as the plasma. After bleeding, the upper part of the abdominal aorta (length $c a .3 \mathrm{~cm}$ ) was removed 
from the adjacent tissues and cleaned in ice-cold saline. The aortas from two rats were minced together in ice-cold chloroform.

Lipid analysis. Lipids of plasma, platelets and aortas were immediately extracted according to the previous

Table I. Fatty Acid Composition of THE DieTaRy OILS

\begin{tabular}{|c|c|c|}
\hline & $\begin{array}{c}\text { Sardine } \\
\text { oil }\end{array}$ & $\begin{array}{c}\text { Corn } \\
\text { oil }\end{array}$ \\
\hline & \multicolumn{2}{|c|}{$\%(w / w)$} \\
\hline $14: 0^{a}$ & 6.8 & - \\
\hline $16: 0$ & 13.8 & 10.9 \\
\hline $16: 1$ & 9.3 & $\mathrm{~T}^{b}$ \\
\hline $18: 0$ & 3.0 & 2.5 \\
\hline $18: 1$ & 13.2 & 40.3 \\
\hline $18: 2$ & 4.3 & 44.1 \\
\hline $18: 3$ & $\mathrm{~T}$ & 1.7 \\
\hline $20: 1$ & 5.2 & $\mathrm{~T}$ \\
\hline $20: 2$ & 4.6 & - \\
\hline $20: 4$ & $\mathrm{~T}$ & - \\
\hline $20: 5$ & 20.9 & - \\
\hline $22: 1$ & 2.9 & - \\
\hline $22: 5$ & 2.4 & - \\
\hline $22: 6$ & 12.1 & - \\
\hline
\end{tabular}

a Number of C-atoms: number of double bonds.

${ }_{b} \mathrm{~T}$, trace amounts (less than $1 \%$ ). paper. ${ }^{11)}$ The individual phospholipids were separated by two-step single dimensional thin-layer chromatography. ${ }^{16)}$ Plates (Merck, Art. 5721) were first developed with chloroform-methanol-acetone-acetic acid-water (100: $50: 100: 4: 10$ by vol.), dried in vacuo for $30 \mathrm{~min}$ and redeveloped in the same direction with chloroformmethanol-acetic acid-water (180:150:30:10 by vol.). Triacylglycerol and free fatty acid were separated with petroleum ether-ethyl ether-acetic acid (70:25:1 by vol.). All the solvents contained $0.005 \%$ BHT. The developed plates were dried in vacuo to remove the solvent. Appropriate areas were scrapped off and their contents were transmethylated with sodium methoxide-methanol (Applied Science Lab. Inc.) at $60^{\circ} \mathrm{C}$ for $20 \mathrm{~min}$, except for the free fatty acid and platelet phosphatidylethanolamine (PE), which were methylated with boron trifluoridemethanol (Applied Science Lab. Inc.) according to the method of Morrison and Smith. ${ }^{17)}$ Methylesters were determined by gas liquid chromatography (GLC, Shimadzu GC-9A) on a column packed with $10 \%$ Silar $10 \mathrm{C}$ on $60 \sim 80$ mesh Neopack $2 \mathrm{~A}$ or $5 \%$ SP-2310 on $100 \sim 120$ mesh Chromosorb $\mathrm{W}$, with an $\mathrm{N}_{2}$ flow rate $40 \mathrm{ml} / \mathrm{min}$ and the temperature programmed from $160^{\circ} \mathrm{C}$ to $240^{\circ} \mathrm{C}$. The fatty acid methylesters were identified by GLC-mass spectrometry (Shimadzu-LKB 9000 GC-MS spectrometer).

Other analysis. Statistical analysis was performed with Student's $t$ test.

Table II. Fatty Acid Composition of Plasma Lipids from Rats Fed on Diets Containing Sardine OR CORn Oil

\begin{tabular}{|c|c|c|c|c|c|c|c|c|}
\hline & \multicolumn{2}{|c|}{ - Phosphatidylcholine } & \multicolumn{2}{|c|}{$\begin{array}{l}\text { Phosphatidyl- } \\
\text { ethanolamine }\end{array}$} & \multicolumn{2}{|c|}{ Triacylglycerol } & \multicolumn{2}{|c|}{ Free fatty acid } \\
\hline & $\mathrm{SO}^{a}$ & $\mathrm{CO}$ & SO & $\mathrm{CO}$ & SO & $\mathrm{CO}$ & SO & $\mathrm{CO}$ \\
\hline & \multicolumn{8}{|c|}{$\%(w / w)$} \\
\hline $16: 0$ & $26.3 \pm 0.5^{b}$ & $18.3 \pm 0.4$ & $10.0 \pm 0.5$ & $13.1 \pm 0.6$ & $16.7 \pm 0.4$ & $15.6 \pm 0.4$ & $20.7 \pm 0.9$ & $20.1 \pm 0.8$ \\
\hline $16: 1$ & $2.2 \pm 0.1$ & $\mathrm{~T}^{c}$ & $\mathrm{~T}$ & $\bar{T}$ & $7.2 \pm 0.2$ & $1.2 \pm 0.1$ & $7.5 \pm 0.5$ & $2.4 \pm 0.3$ \\
\hline $18: 0$ & $16.9 \pm 0.5$ & $24.3 \pm 0.5$ & $26.4 \pm 0.5$ & $23.8 \pm 1.4$ & $1.7 \pm 0.1$ & $2.2 \pm 0.0$ & $3.6 \pm 0.7$ & $4.8 \pm 0.4$ \\
\hline $18: 1$ & $9.3 \pm 0.3$ & $7.3 \pm 0.2$ & $9.1 \pm 0.4$ & $12.8 \pm 1.5$ & $17.1 \pm 0.3$ & $35.0 \pm 0.8$ & $13.9 \pm 1.2$ & $30.9 \pm 0.8$ \\
\hline $18: 2$ & $4.1 \pm 0.1$ & $19.0 \pm 0.9$ & $1.2 \pm 0.1$ & $12.8 \pm 2.0$ & $3.8 \pm 0.2$ & $36.1 \pm 0.7$ & $4.4 \pm 0.2$ & $32.8 \pm 1.3$ \\
\hline $18: 3$ & $\mathrm{~T}$ & $\mathrm{~T}$ & $\mathrm{~T}$ & $\mathrm{~T}$ & $1.2 \pm 0.0$ & $\mathrm{~T}$ & $1.2 \pm 0.0$ & $\mathrm{~T}$ \\
\hline $20: 1$ & $\mathrm{~T}$ & $\mathrm{~T}$ & $1.4 \pm 0.2$ & $\mathrm{~T}$ & $5.5 \pm 0.4$ & $\mathrm{~T}$ & $4.5 \pm 0.4$ & $\mathrm{~T}$ \\
\hline $20: 4$ & $8.4 \pm 0.1$ & $25.6 \pm 0.8$ & $6.4 \pm 0.2$ & $21.5 \pm 1.1$ & $\mathrm{~T}$ & $5.3 \pm 0.7$ & $2.9 \pm 0.3$ & $5.8 \pm 0.5$ \\
\hline $20: 5$ & $18.6 \pm 1.2$ & - & $15.1 \pm 0.6$ & - & $22.5 \pm 0.4$ & - & $18.3 \pm 1.4$ & - \\
\hline $22: 1$ & $\mathrm{~T}$ & - & $\mathrm{T}$ & - & $2.1 \pm 0.1$ & - & $1.4 \pm 0.1$ & - \\
\hline $22: 4$ & $\mathrm{~T}$ & $\mathrm{~T}$ & $\mathrm{~T}$ & $6.2 \pm 0.9$ & $\overline{\mathrm{T}}$ & $\mathrm{T}$ & $\mathrm{T}$ & $\mathrm{T}$ \\
\hline $22: 5$ & $1.2 \pm 0.2$ & $\mathrm{~T}$ & $3.4 \pm 0.3$ & $\mathrm{~T}$ & $3.5 \pm 0.2$ & $\mathrm{~T}$ & $3.6 \pm 0.3$ & - \\
\hline $22: 6$ & $11.1 \pm 0.9$ & $4.6 \pm 0.2$ & $25.0 \pm 0.6$ & $7.8 \pm 0.7$ & $17.1 \pm 0.3$ & $\mathrm{~T}$ & $17.7 \pm 1.3$ & $\mathrm{~T}$ \\
\hline Others $^{d}$ & 1.2 & $\mathrm{~T}$ & 1.0 & $\mathrm{~T}$ & 1.0 & 2.5 & $\mathrm{~T}$ & 1.5 \\
\hline
\end{tabular}

a SO, sardine oil; CO, corn oil.

$b \quad$ Values are means \pm SEM of 7 samples.

c $\mathrm{T}$, trace amounts (less than $1 \%$ ).

d Others, 20:2;20:3. Each of these fatty acids was less than $1 \%$. 


\section{RESULTS AND DISCUSSION}

Effects of the SO or CO diet on the fatty acid composition of lipids in various tissues

The fatty acid compositions of plasma triacylglycerol and free fatty acid (FFA) in rats fed on the SO or $\mathrm{CO}$ diet for 10 days were similar to those of the respective oils (Tables I and II). In plasma phosphatidylcholine (PC) and $\mathrm{PE}$, there were accumulations of $20: 5$ and $22: 6$ (docosahexaenoic acid) in rats fed on the SO diet, and 18:2 and 20:4 in rats fed on the $\mathrm{CO}$ diet.

Table III shows the fatty acid compositions of phospholipid classes in platelets and aortas of rats fed on the SO or CO diet for 10 days. The proportions of $20: 4,20: 5$ and $22: 6$ in PC were higher in the aortas than in the platelets. The $20: 5 / 20: 4$ ratios of PC were 5.0 and 1.1 in platelets and aortas, respectively. The platelet $\mathrm{PE}$ of rats fed on the SO diet accumulated

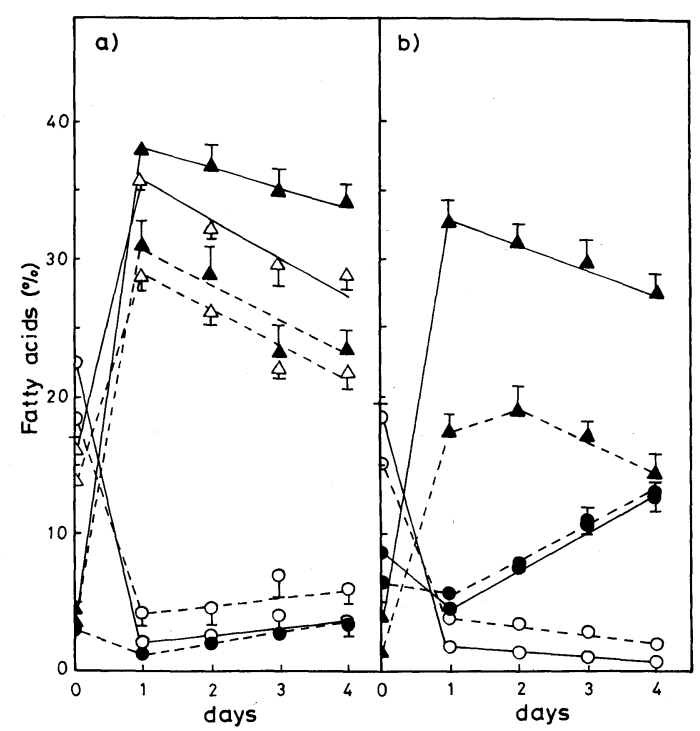

FIG. 1. Dynamic Changes in the Fatty Acid Composition of Plasma Lipids after Changing from the Sardine Oil Diet to the Corn Oil Diet.

After rats had been fed on the diet containing sardine oil (SO) for 10 days, the diet was changed to corn oil (CO). During feeding with the CO diet, the proportion of $18: 1$ $(\triangle), 18: 2(\Delta), 20: 4(\mathbf{O})$ and 20:5 (O) in the plasma lipids were analyzed. Values are means $\pm \operatorname{SEM}(n=7)$. (a) Plasma triacylglycerol (-) and free fatty acid (-- ), (b) plasma phosphatidylcholine (-) and phosphatidylethanolamine (--- ). large amounts of $20: 5$ and $22: 5$ (docosapentaenoic acid), differently from the aorta PE. The proportions of $18: 2$ of platelet and aorta $\mathrm{PE}$ in rats fed on the $\mathrm{CO}$ diet were only a few percent. Only $3 \%$ of $20: 5$ was accumulated in the aorta phosphatidylserine (PS) of rats fed on the SO diet; however, a large amount of $22: 6$ was incorporated into the PS. The proportion of 20:4 in the aorta PS of rats fed on the $\mathrm{CO}$ diet was $13 \%$, this being one-third that of the platelet PS. Galli et al. have reported that the proportion of $20: 4$ in aorta PS was low in the rabbit. ${ }^{18)}$ As is well known, the major fatty acids were 18:0 and 20:4 in the platelet or aorta phosphatidylinositol (PI). The proportion of 20:5 in PI was higher in plate-

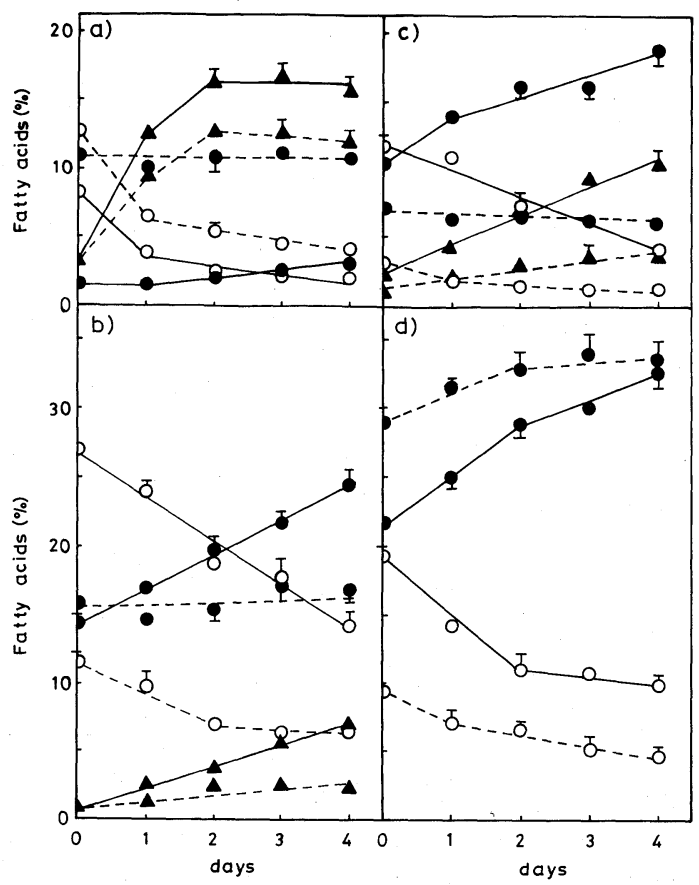

FIG. 2. Dynamic Changes in the Fatty Acid Composition of Platelet and Aorta Phospholipids after Changing from the Sardine Oil Diet to the Corn Oil Diet.

After rats had been fed on the diet containing sardine oil (SO) for 10 days, the diet was changed to corn oil (CO). During feeding with the $\mathrm{CO}$ diet, the proportions of $18: 2$ (A), 20:4 (O) and 20:5 (O) of the platelet (-) and aorta (---) phospholipids were analyzed. Values are means \pm SEM of 7 samples for platelets and 3 samples composed of 2 rats for aortas. (a) Phosphatidylcholine, (b) phosphatidylethanolamine, (c) phosphatidylserine and (d) phosphatidylinositol. 
Table III-1. Fatty Acid Composition of Phosphatidylcholine and Phosphatidylethanolamine in Platelets and Aortas from Rats Fed on Diets Containing Sardine or CORN OIL FOR 10 DAYS

\begin{tabular}{|c|c|c|c|c|c|c|c|c|}
\hline & \multicolumn{4}{|c|}{ Phosphatidylcholine } & \multicolumn{4}{|c|}{ Phosphatidylethanolamine } \\
\hline & \multicolumn{2}{|c|}{ Platelet } & \multicolumn{2}{|c|}{ Aorta } & \multicolumn{2}{|c|}{ Platelet } & \multicolumn{2}{|c|}{ Aorta } \\
\hline & $\mathrm{SO}^{a}$ & $\mathrm{CO}$ & SO & $\mathrm{CO}$ & SO & $\mathrm{CO}$ & SO & $\mathrm{CO}$ \\
\hline \multicolumn{9}{|c|}{$\%(w / w)$} \\
\hline $16: 0 \mathrm{ad}^{b}$ & - & - & - & - & $3.4 \pm 1.3^{c}$ & $5.7 \pm 0.2$ & $8.0 \pm 0.5$ & $8.6 \pm 0.3$ \\
\hline $16: 0$ & $59.5 \pm 0.5$ & $62.5 \pm 0.6$ & $32.6 \pm 0.8$ & $35.0 \pm 0.5$ & $6.8 \pm 0.9$ & $6.0 \pm 0.1$ & $9.2 \pm 0.1$ & $5.8 \pm 0.0$ \\
\hline $16: 1$ & $4.7 \pm 0.2$ & $1.4 \pm 0.1$ & $2.5 \pm 0.0$ & $\mathrm{~T}^{\bar{d}}$ & $\mathrm{~T}$ & $\mathrm{~T}$ & $1.5 \pm 0.1$ & $\mathrm{~T}$ \\
\hline $18: 0 \mathrm{ad}$ & - & - & - & - & $3.5 \pm 1.3$ & $6.9 \pm 0.2$ & $7.5 \pm 1.3$ & $7.3 \pm 0.1$ \\
\hline $18: 0$ & $6.1 \pm 0.1$ & $7.8 \pm 0.2$ & $15.4 \pm 0.5$ & $15.4 \pm 0.2$ & $15.6 \pm 1.1$ & $13.8 \pm 1.2$ & $23.7 \pm 0.3$ & $19.9 \pm 0.1$ \\
\hline 18: 1ad & - & - & - & - & $1.7 \pm 0.6$ & $5.5 \pm 0.3$ & $\overline{\mathrm{T}}$ & $\bar{T}$ \\
\hline $18: 1$ & $11.0 \pm 0.1$ & $7.5 \pm 0.1$ & $12.3 \pm 0.2$ & $11.6 \pm 0.2$ & $6.3 \pm 0.9$ & $6.8 \pm 0.1$ & $8.1 \pm 0.4$ & $8.3 \pm 0.3$ \\
\hline $18: 2$ & $3.3 \pm 0.1$ & $9.3 \pm 0.4$ & $3.2 \pm 0.1$ & $8.9 \pm 0.3$ & $1.0 \pm 0.1$ & $3.1 \pm 0.1$ & $1.1 \pm 0.1$ & $2.8 \pm 0.1$ \\
\hline $20: 4$ & $1.7 \pm 0.0$ & $9.3 \pm 0.3$ & $11.1 \pm 0.4$ & $22.9 \pm 0.7$ & $14.3 \pm 0.3$ & $35.1 \pm 0.7$ & $15.7 \pm 0.7$ & $28.5 \pm 0.3$ \\
\hline $20: 5$ & $8.5 \pm 0.2$ & - & $12.7 \pm 0.8$ & - & $26.9 \pm 0.2$ & - & $11.6+0.5$ & - \\
\hline $22: 1$ & $1.2 \pm 0.0$ & - & $\mathrm{T}$ & - & $1.4 \pm 0.0$ & - & $1.0 \pm 0.0$ & - \\
\hline $22: 4$ & $T$ & $\mathrm{~T}$ & $\mathrm{~T}$ & $2.4 \pm 0.1$ & $\bar{T}$ & $13.1 \pm 0.2$ & $2.4 \pm 0.1$ & $12.3 \pm 0.2$ \\
\hline $22: 5$ & $\mathrm{~T}$ & $\mathrm{~T}$ & $1.9 \pm 0.1$ & $\bar{T}$ & $11.8 \pm 0.2$ & $\bar{T}$ & $2.0 \pm 0.4$ & $2.6 \pm 0.2$ \\
\hline $22: 6$ & $1.2 \pm 0.0$ & $\mathrm{~T}$ & $6.4 \pm 0.2$ & $1.5 \pm 0.1$ & $4.6 \pm 0.1$ & $1.4 \pm 0.0$ & $6.4 \pm 0.2$ & $\bar{T}$ \\
\hline Others $^{e}$ & $1 . \overline{8}$ & 1.0 & 1.0 & 1.3 & 2.0 & 2.0 & 1.5 & 2.0 \\
\hline
\end{tabular}

a SO, sardine oil; CO, corn oil.

$b$ ad, dimethylacetal derivatives of aldehydes.

c Values are means \pm SEM of 7 samples for platelets and 3 samples composed of 2 rats for aortas.

${ }^{d} \mathrm{~T}$, trace amounts (less than $1 \%$ ).

$e$ Others, $18: 3 ; 20: 1 ; 20: 3 ; 22: 0$. Each of these fatty acids was less than $1 \%$.

lets than in aortas, and $50 \%$ of $20: 4$ in the platelet PI was substituted with $20: 5$.

Changes of 18:2, 20:4 and 20:5 of lipids in various tissues after changing from the $\mathrm{SO}$ diet to the $\mathrm{CO}$ diet

The density of collagen-induced aggregation of washed platelets in rats fed on the SO diet was reduced to $72 \%$ of that in rats fed on the $\mathrm{CO}$ diet. ${ }^{15)}$ However, after the diet had been changed from SO to $\mathrm{CO}$, this depressed aggregation was gradually restored. ${ }^{15)}$ Thelevels of $18: 1,18: 2,20: 4$ and $20: 5$ in the platelet, aorta and plasma lipids were examined. In the triacylglycerol, FFA, PC and PE of plasma, the level of $20: 5$ decreased markedly by feeding with the $\mathrm{CO}$ diet and the levels of $18: 1$ and $18: 2$ increased rapidly (Fig. 1). $20: 4$ increased gradually after day 1 .

On day 1 , the level of $20: 5$ in the platelet and aorta PC reduced to $50 \%$ of that at day 0 , with a marked increase in 18:2 (Fig. 2a). Although the 20:4 of platelet PC increased significantly $(p<0.001$, day $0 v s$. day 4$)$, that of aorta PC did not change during feeding with the $\mathrm{CO}$ diet for 4 days. The $20: 5 / 20: 4$ ratios of the PC in platelets and aortas varied from 5.0 and 1.1 to 2.4 and 0.6 , respectively, on day 1. In the platelet PE, $20: 5$ was partially substituted by $20: 4$ upon feeding with the $\mathrm{CO}$ diet. However, 20:4 of the aorta PE did not increase as did that of the aorta PC. The level of $18: 2$ in PE increased more slowly than that in PC. Contrary to the platelet PC, the profiles of changes in 18:2 and 20:4 of the platelet PE were not similar to those of the plasma PE (Figs. $1 \mathrm{~b}$ and $2 \mathrm{a}$, Figs. $1 \mathrm{~b}$ and $2 \mathrm{~b}$ ). The level of $20: 5$ in platelet PS decreased, and 18:2 and 20:4 increased (Fig. 2c). The levels of 20:4 and 20:5 in aorta PS remained unchanged during the $\mathrm{CO}$ diet for 4 days. The level of 20:5 in platelet PI decreased with an 
Table III-2. Fatty Acid Composition of Phosphatidylserine and Phosphatidylinositol in Platelets and Aortas from Rats Fed on Diets Containing Sardine or Corn Oil for 10 Days

\begin{tabular}{|c|c|c|c|c|c|c|c|c|}
\hline & \multicolumn{4}{|c|}{ Phosphatidylserine } & \multicolumn{4}{|c|}{ Phosphatidylinositol } \\
\hline & \multicolumn{2}{|c|}{ Platelet } & \multicolumn{2}{|c|}{ Aorta } & \multicolumn{2}{|c|}{ Platelet } & \multicolumn{2}{|c|}{ Aorta } \\
\hline & $\mathrm{SO}^{a}$ & $\mathrm{CO}$ & SO & $\mathrm{CO}$ & $\mathrm{SO}$ & $\mathrm{CO}$ & SO & $\mathrm{CO}$ \\
\hline \multicolumn{9}{|c|}{$\%(\mathrm{w} / \mathrm{w})$} \\
\hline $16: 0$ & $\mathrm{~T}^{b}$ & $1.3+0.2^{c}$ & $2.2 \pm 0.0$ & $1.2 \pm 0.1$ & $3.9 \pm 0.2$ & $4.9 \pm 0.7$ & $4.9 \pm 0.2$ & $1.9 \pm 0.8$ \\
\hline $18: 0$ & $34.3 \pm 0.4$ & $37.0 \pm 0.4$ & $41.5 \pm 0.2$ & $43.1 \pm 0.3$ & $35.8 \pm 1.0$ & $35.1 \pm 0.8$ & $39.7 \pm 0.9$ & $42.0 \pm 0.7$ \\
\hline $18: 1$ & $7.7 \pm 0.3$ & $7.3 \pm 0.2$ & $17.6 \pm 0.5$ & $21.5 \pm 0.9$ & $4.6 \pm 0.3$ & $6.1 \pm 0.3$ & $3.7 \pm 1.2$ & $4.6 \pm 0.2$ \\
\hline $18: 2$ & $2.7 \pm 0.2$ & $4.4 \pm 0.5$ & $1.6 \pm 0.1$ & $2.4 \pm 0.1$ & $\bar{T}$ & $2.5 \pm 0.4$ & $2.5 \pm 0.9$ & $1.5 \pm 0.2$ \\
\hline $20: 2$ & $1.1 \pm 0.0$ & $3.2 \pm 0.1$ & $\bar{T}$ & $T$ & $\mathrm{~T}$ & $\mathrm{~T}$ & $\mathrm{~T}$ & $\mathrm{~T}$ \\
\hline $20: 3$ & $1.3+0.0$ & $2.1 \pm 0.1$ & $1.9 \pm 0.0$ & $2.8 \pm 0.0$ & $\mathrm{~T}$ & $\mathrm{~T}$ & $\mathrm{~T}$ & $\mathrm{~T}$ \\
\hline $20: 4$ & $10.6 \pm 0.2$ & $36.9 \pm 0.4$ & $7.0 \pm 0.4$ & $12.7 \pm 0.3$ & $21.4 \pm 0.4$ & $43.8 \pm 0.9$ & $29.0 \pm 0.9$ & $44.6 \pm 2.8$ \\
\hline $20: 5$ & $11.8 \pm 0.4$ & - & $3.0 \pm 0.2$ & - & $19.3 \pm 0.3$ & - & $9.4 \pm 0.5$ & - \\
\hline $22: 0$ & $7.6 \pm 0.1$ & - & - & - & $1.7 \pm 0.4$ & - & - & - \\
\hline $22: 1$ & $7.8 \pm 0.2$ & - & $\mathrm{T}$ & - & $2.3 \pm 0.0$ & - & $\mathrm{T}$ & - \\
\hline $22: 4$ & $\mathrm{~T}$ & $4.6+0.1$ & $2.5 \pm 0.1$ & $9.3 \pm 0.6$ & $\bar{T}$ & $3.5 \pm 0.3$ & $1.3 \pm 0.6$ & $3.3 \pm 1.3$ \\
\hline $22: 5$ & $8.2 \pm 0.2$ & $\mathrm{~T}$ & $7.2 \pm 0.4$ & $1.4 \pm 0.0$ & $7.1 \pm 0.3$ & $1.3 \pm 0.3$ & $2.6 \pm 0.1$ & $\overline{\mathrm{T}}$ \\
\hline $22: 6$ & $3.9 \pm 0.2$ & $1.0 \pm 0.1$ & $13.5 \pm 0.4$ & $4.2 \pm 0.3$ & $2.8 \pm 0.2$ & $\mathrm{~T}$ & $4.9 \pm 1.0$ & $1.0 \pm 0.8$ \\
\hline Others $^{d}$ & $1 . \overline{8}$ & 1.2 & $1 . \overline{2}$ & 1.0 & $\bar{T}$ & 2.2 & $\bar{T}$ & $\bar{T}$ \\
\hline
\end{tabular}

$a \sim c \quad$ See footnote to Table III-1.

d Others, $16: 1 ; 18: 3 ; 20: 1$. Each of these fatty acids was less than $1 \%$.

increase of 20:4 (Fig. 2d). However, the change in $20: 4$ of aorta PI was small and not significant ( $p<0.1$, day $0 v s$. day 4 ). There was little change of $18: 2$ in the PI of platelets and aortas.

Since there was a large amount of $20: 5$ in SO (Table I), this fatty acid was markedly incorporated into the platelet and aorta phospholipids, compared with the results from other papers ${ }^{5,9}$ (Table III). Changing from the $\mathrm{SO}$ diet to the $\mathrm{CO}$ diet caused changes to the levels of $18: 2,20: 4$ and $20: 5$ in the platelet and aorta phospholipids (Fig. 2). The rates of increase in 20:4 were similar in platelet PE, PS and PI. 20:4 in the plasma FFA was probably incorporated into these phospholipids. Contrary to these phospholipids, 20:4 increased slowly in the platelet PC, but $18: 2$ increased rapidly during feeding with the $\mathrm{CO}$ diet. These changes were similar to those of the plasma PC (Figs. 1b and 2a), which implies an exchange of platelet $\mathrm{PC}$ with plasma PC, as indicated by Béréziat et al. ${ }^{19)}$ However, the level of $20: 4$ in all the phospholipids in aortas scarcely changed during feeding with the $\mathrm{CO}$ diet for 4 days. This suggests that $20: 4$ in the plasma lipids was not incorporated into the aorta phospholipids. Therefore, 20:4 and 20:5 in the platelet phospholipids may be substituted by each other, whereas this substitution was not seen in the aortas. On the other hand, it seems likely that 18:2 in the plasma lipids was selectively incorporated into $\mathrm{PC}$ in the aortas.

Different modes of changes were seen in $20: 5$ between the platelet PC and PE (Fig. 2a and $2 b$ ) after the diet had been changed. This may be due to differences in the localization of phospholipids containing 20:5 in platelet membranes and/or differences in the specificity of an exchange reaction between the membrane phospholipids and plasma lipids. ${ }^{19 \sim 22)}$

\section{REFERENCES}

1) J. Dyerberg and H. O. Bang, Haemostasis, 8, 227 (1979).

2) J. Dyerberg and H. O. Bang, "Advances in Nutritional Research," Vol. 3, ed. by H. H. Draper, Plenum Press, New York, 1980, pp. 1 22.

3) F. ten Hoor, E. A. M. de Decker, E. Haddeman, G. 
Hornstra and J. F. A. Quadt, "Advances in Prostaglandin and Thromboxane Research," Vol. 8, ed. by B. Samuelson, P. Ramwell and R. Paoletti, Raven Press, New York, 1980, pp. 1771 1781.

4) C. Galli, "Advances in Nutritional Research," Vol. 3, ed. by H. H. Draper, Plenum Press, New York, 1980, pp. $95 \sim 126$.

5) A. Socini, C. Galli, C. Colombo and F. Tremoli, Prostagrandins, 25, 693 (1983).

6) E. Giani, I. Masi, C. Colombo and C. Galli, Prostaglandins, 28, 573 (1984).

7) P. Budowski, Isr. J. Med. Sci., 17, 223 (1981).

8) W. Siess, B. Scherer, B. Böhlig, O. Roth, I. Kurzmann and P. Weber, Lancet, ii, 1749 (1979).

9) G. Hornstra, E. Chist-Hazelhof, E. Haddeman, F. ten Hoor and D. H. Nugteren, Prostaglandins, 21, 727 (1981).

10) F. W. vas Dias, M. J. Gibney and T. G. Taylor, Atherosclerosis, 43, 245 (1982).

11) M. Ishinaga, M. Kakuta, H. Narita and M. Kito, Agric. Biol. Chem., 47, 903 (1983).
12) J. H. Brox, J.-E. Killie, S. Gunnes and A. Nordøy, Thromb. Haemost. (Stuttgart), 46, 604 (1981).

13) A. A. Ahmed and B. J. Holub, Lipids, 19, 617 (1984).

14) W. E. Lockette, R. C. Webb, B. R. Culp and B. Pitt, Prostaglandins, 24, 631 (1982).

15) M. Kito, H. Narita, M. Ishinaga, H. J. Park and H. Takamura, J. Biochem., 97, 765 (1985).

16) M. Ishinaga, J. Sato, Y. Kitagawa, E. Sugimoto and M. Kito, J. Biochem., 92, 253 (1982).

17) W. R. Morrison and L. M. Smith, J. Lipid Res., 5, 600 (1964).

18) C. Galli, E. Agradi, A. Petroni and E. Tremoli, Lipids, 16, 165 (1981).

19) G. Béréziat, J. Chambag, G. Trugnan, D. Pepin and J. Polonovski, J. Lipid Res., 19, 495 (1978).

20) J. H. Joist, G. Dolezel, J. V. Lloyd and J. F. Mustard, Blood, 48, 199 (1976).

21) H. J. Chap, R. F. A. Zwaal and L. L. M. Deenen, Biochim. Biophys. Acta, 267, 146 (1977).

22) P. K. Schik, B. P. Schik, G. Brandeis and D. C. B. Mills, Biochim. Biophys. Acta, 643, 659 (1981). 